\title{
Negative Effects and Factors Associated with Postpartum Depression on both Vaginal and Cesarean Delivery Groups
}

\author{
Hadi Razmyar $^{1 *}$, Shiva Radvar $^{2}$
}

\section{ABSTRACT}

Background and objectives: Postpartum depression is highly prevalent and a broad range of causes including types of delivery are introduced as its source. This study aimed to investigate the relationship between types of delivery and the prevalence of postpartum depression. Methods: This cross-sectional study was carried out in the maternity ward of Sina hospital, Mashhad, in 2014. To this end, 300 women referring to delivery ward were selected through convenient sampling and examined 4 times (immediately after childbirth, 4 weeks after the first assessment, 6 weeks after the second assessment, and 8 weeks after the third assessment) using a demographic questionnaire and Beck's Depression Inventory. In this regard, the first assessment was conducted in person and other assessments were conducted by researcher through making phone calls. Those mothers taking psychiatric medication, having children with serious physical health problem, and having obtained a score above 14 for the first assessment based on the Beck's Depression Inventory as well as those for whom it was not possible to making phone calls were excluded from the study. Data was analyzed using the SPSS software and the confidence level was set at .05. Findings: There was no significant difference between two groups in terms of education, occupation, economic status, being satisfied with their husbands' support and family and planned and unplanned pregnancy. The prevalence of depression was 10.3 percent two weeks after childbirth and it was 13 percent for mothers during the $8^{\text {th }}$ weeks after childbirth. However, this difference was not statistically significant. Conclusions: The postpartum depression of high prevalence; therefore, adjusting each of the relevant factors is useful for reducing the incidence of depression.

Keywords: Postpartum Depression, Postpartum Period, Delivery, Cesarean, Vagina

Pregnancy and postpartum period are associated with important psychological and physiological changes which sometimes lead to pathological changes and mental disorders .Postpartum psychiatric disorders, including postpartum depression creates lots of problems for mothers and

\footnotetext{
${ }^{1}$ Instructor, Quchan Branch, Islamic Azad University, Quchan, Iran

${ }^{2}$ Instructor, Quchan Branch, Islamic Azad University, Quchan, Iran

*Responding Author

(C) 2016 H Razmyar, S Radvar; licensee IJIP. This is an Open Access Research distributed under the terms of the Creative Commons Attribution License (http://creativecommons.org/licenses/by/2.0), which permits unrestricted use, distribution, and reproduction in any Medium, provided the original work is properly cited.
} 


\section{Negative Effects and Factors Associated with Postpartum Depression on both Vaginal and Cesarean Delivery Groups}

other family members. Such a situation may affect mother-infant affection and other family relationships and can even be a threat to the mother, infant and other children's security and health (1). No specific mechanism is proposed for developing postpartum depression after cesarean delivery. It may be caused by longer hospital stay, anesthesia and surgical complications and later return to daily activities (2-3). Regarding the well-known complications of cesarean delivery and its growing trend, especially in developing countries, further investigations on its potential harmful effects on mothers and infants is of essence (5-4).

For this reason and given the contradictory findings associated with cesarean delivery and postpartum depression, the present study taking disturbing factors into account examines the relationship between these two variables (7-6). When an infant's mother is expecting delightful experiences in life, she also tackles with unknown and unpleasant feelings of anxiety, helplessness, lack of pleasure, sleep and appetite disorders, lack of confidence and inadequacy as a parent. In postpartum depression, the patient experiences increased appetite and weight gain . The desire to sleep increases during this period, especially among nulliparous mothers; however, they get up at a sound of a baby's cries and are unable to go to asleep again. Some symptoms of postpartum depression include irritability, spontaneous and uncontrolled crying, explosive and aggressive behavior, severe anxiety, panic attacks, fear and tendency to loneliness. One of the most prominent features of postpartum depression is rejecting the baby due to the mother's abnormal anger. An important and warning issue which shall be concerned is psychiatric symptoms such as suicidal thoughts and large disturbances in sleeping pattern (8). As it was mentioned above, the method of delivery is considered as a risk factor for postpartum depression. Research carried out in this field revealed conflicting results. The results of the study conducted by Aponge et al. Showed that women with cesarean deliver are more likely to experience postpartum depression (9). Dolatian et al. and Farzad et al. also concluded that women are more prone to postpartum depression after caesarean delivery. In contrast, research findings obtained by Chaaya et al. and Salmanian et al. showed that postpartum depression in women undergoing cesarean delivery is less in comparison with women undergoing vaginal delivery. Some researchers also concluded that there is no relationship between method of delivery and postpartum depression. Regarding the controversies of the results and unknown factors in more than 50 percent of the cases, causing enormous problems for mothers and infants, identifying risk factors for this disorder seems essential. Hence, this study aimed to determine the relationship between types of delivery and postpartum depression in women referring to Amol health care centers, Iran, during the $2^{\text {nd }}$ and $8^{\text {th }}$ weeks after delivery. Limited research has been conducted on mental complications of cesarean delivery and other obstetric surgeries (10). After reviewing the studies done by other researchers, Clement mentioned that in 18 studies women undergoing cesarean delivery were less satisfied with birth experience and in other eleven studies women after vaginal delivery were more depressed than women having cesarean delivery; however, in another 9 studies no difference was observed between the two groups in terms of depression 


\section{Negative Effects and Factors Associated with Postpartum Depression on both Vaginal and Cesarean Delivery Groups}

(11). Carter et al. also investigated the results of twenty-four studies entitled cesarean delivery and postpartum depression and a relationship was observed between these two variables in 5 cases; however, no correlation was found in other fifteen studies (12). In other studies, it is indicated that cesarean delivery can cause negative psychological effects in some women so that the sense of deprivation, guilt or failure due to lack of natural childbirth provides conditions for increased compatibility problems in mothers (14-13). The cause of this disease is still unknown; however, there are some theories on the etiology of postpartum depression and include biological factors (such as hormonal causes such as a sudden drop in estrogen levels and increased urinary excretion of cortisol, vectors, neurological factors and genetic theories); psychological factors (e.g. personality theories) and social factors (such as social support, stress, life, culture and preparation for childbirth) (15). In a study conducted in Kerman, such postpartum depression was more prevalent among nulliparous mothers and those mothers having a history of abortion, child death and unplanned pregnancies. The importance of the child gender for the mother and greater number of children also showed a significant relationship with the increased prevalence of depression. In addition to the harmful effects of postpartum depression on the mother-child relationship, disrupts mothers' relationships with their husbands and the husbands of depressed women often become depressed, which, if untreated, may lead to separation and divorce (16).

Rapid detection and differentiation of the symptoms from the postpartum sadness is one of the major tasks of the treatment group. Medical group (including general practitioners, midwives and family planning experts and vaccination group) should be able to identify those who are prone to postpartum mental disorders (particularly postpartum depression) and gives them some advices on health care and support during this period (17). In this regard, treatment with Selective serotonin re-uptake inhibitors (SSRIS), psychotherapy (sometimes as a treatment method and sometimes as a way to increase the medication acceptance by the patient), and, in severe cases, hospitalization are recommended. Having a history of depression, depression during pregnancy, and risk factors make follow-up care necessary (19-18).

This study aimed to identify risk factors and prevalence of postpartum depression and to make relevant experts working in the health centers aware of this disorder in order to prevent adverse effects of the disorder on the mothers and infants' health in Zahedan.

\section{METHODOLOGY}

This study is a cross-sectional study conducted in Mashhad at Sinai Hospital during 2014. According to previous studies, 300 patients were selected based on convenient sampling. Those mothers taking psychiatric medication, having children with serious physical health problem, and having obtained a score above 14 for the first assessment based on the Beck's Depression Inventory as well as those for whom it was not possible to making phone calls were excluded from the study. The participants were assessed four times (first assessment in person and other 


\section{Negative Effects and Factors Associated with Postpartum Depression on both Vaginal and Cesarean Delivery Groups}

times by). The first assessment was conducted at the first day of delivery (before discharge). The second, third, and fourth assessments were run during the fourth week (first month after childbirth), during the tenth week (2.5 months after childbirth), and during the $18^{\text {th }}$ week (5.4 months after childbirth), respectively.

Data was collected using a demographic questionnaire including age, education level, occupation, number of pregnancies, number of children, history of abortion, history of child death, type of delivery, infant's gender, planned and unplanned pregnancy, wanted and unwanted infant's gender in terms of the patient, wanted and unwanted infant's gender in terms of the husband, history of depression, history of visiting psychiatrist, and psychiatric medicines, and infants' breastfeeding method and the Beck's Depression Inventory.

Beck's Depression Inventory was first introduced in 1961 by Beck et al., revised in 1971 and finally published in 1978. This tool is well-known since, during 30 years of its development, it has been employed in more than 1000 research studies. In Iran, this test was standardized by Okhovat and is widely used to measure depression in normal subjects and patients with mental disorders. The Beck's Depression Inventory is not culture specific and is applicable for different social classes including rich and poor subjects. In this test, the respondents are asked to scale the severity of symptoms from 0-3.

The questionnaire is related to some areas such as feelings of failure, guilt, irritability, sleep disorder and lack of appetite and so on. The questionnaire is a self-report test and it takes 5-10 minutes to complete it.

Since its development (30 years ago), its reliability and validity has been extensively assessed based on psychometric factors. A high-level analysis of the various attempts to determine its internal consistency has shown that the coefficients vary from 0.73 to 2 with the mean of 0.86 for the common 21-item version. Steer, Beck, Brown, and Berjik reported that patients with major depression disorders compared with those having dysthymic disorder receive relatively higher scores. The 21-item version is used in this study and the responses were scored as follows: 0-14 as natural persons or people with normal levels of depression, 15-31 people with mild depression, 32-47 moderate depression, and 48-63 individuals with severe depression. At each turn of assessment, patients with scores above 14 were excluded after being referred to a psychiatrist. Finally, data were analyzed using tables and descriptive and analytical statistics as well as Chi-square tests in the SPSS software.

\section{FINDINGS}

In this study, 310 pregnant women (154 women in vaginal delivery and 156 women in cesarean delivery groups) were examined. The specifications of the participants are presented in Table 1.

(c) The International Journal of Indian Psychology, ISSN 2348-5396 (e)| ISSN: 2349-3429 (p) | 174 


\section{Negative Effects and Factors Associated with Postpartum Depression on both Vaginal and Cesarean Delivery Groups}

Table 1: A comparison between the specifications of the studied groups and postpartum depression

\begin{tabular}{|c|c|c|c|c|}
\hline \multicolumn{2}{|c|}{ Variables } & $\begin{array}{l}\text { Vaginal delivery } \\
\text { group ( } \mathrm{n}=154)\end{array}$ & $\begin{array}{l}\text { Cesarean delivery } \\
\text { group ( } \mathrm{n}=156)\end{array}$ & $\mathbf{p}$ \\
\hline \multicolumn{2}{|c|}{ Mean age(standard deviation) } & 26.24 & 27.44 & 0.05 \\
\hline \multicolumn{2}{|c|}{ Mean age of husband (standard deviation) } & 3.33 & 31.3 & 0.13 \\
\hline \multirow{3}{*}{$\begin{array}{l}\text { Occupation } \\
\text { (\%) }\end{array}$} & housewife & 143 & 146 & \multirow{3}{*}{0.797} \\
\hline & employed & & & \\
\hline & & 11 & 10 & \\
\hline \multirow[t]{3}{*}{ Education level } & illiterate & 3 & 4 & \multirow{3}{*}{0.89} \\
\hline & Below diploma & 76 & 79 & \\
\hline & $\begin{array}{l}\text { Diploma and } \\
\text { academic degree }\end{array}$ & 75 & 73 & \\
\hline \multirow{3}{*}{$\begin{array}{l}\text { Husband's education } \\
\text { level }\end{array}$} & illiterate & 2 & 2 & \multirow{3}{*}{0.69} \\
\hline & Below diploma & 80 & 88 & \\
\hline & $\begin{array}{l}\text { Diploma and } \\
\text { academic degree }\end{array}$ & 70 & 66 & \\
\hline \multirow[t]{3}{*}{ Income level } & high & \multirow{3}{*}{$\begin{array}{c}16 \\
101 \\
37\end{array}$} & \multirow{3}{*}{$\begin{array}{c}16 \\
193 \\
46\end{array}$} & \multirow{3}{*}{0.52} \\
\hline & medium & & & \\
\hline & low & & & \\
\hline \multicolumn{2}{|c|}{ A history of premenstrual syndrome (\%) } & 89 & 54 & 0.001 \\
\hline \multicolumn{2}{|c|}{ Being satisfied with the infant's gender (\%) } & 129 & 126 & 0.59 \\
\hline \multicolumn{2}{|c|}{$\begin{array}{l}\text { mean number of prenatal care } \\
\text { (standard deviation) }\end{array}$} & 12 & 24 & 0.03 \\
\hline \multicolumn{2}{|l|}{ Pregnancy problems (\%) } & 54 & 53 & 0.522 \\
\hline \multicolumn{2}{|l|}{ Abortion (\%) } & 53 & 35 & 0.42 \\
\hline
\end{tabular}

The mean age of women in the vaginal delivery group was $66.5 \pm 26.25$ years and it was significantly lower than the cesarean delivery group $(\mathrm{p}<.05)$. There was no significant difference between two groups in terms of occupation, patients and their husbands' education level, income level, and satisfaction from infants' genders. The mean numbers of prenatal care were 11.51 and 12.03 in the vaginal delivery and cesarean delivery groups, respectively. The observed difference was not statistically significant ( $\mathrm{p}=.52) .89$ (57.8\%) patients reported a history of premenstrual syndrome in the vaginal delivery group; however, this was 5.3\% for another group. The observed difference was statistically significant $(\mathrm{p}=.001)$. The history of abortion in the vaginal delivery group was $7 \%$ and it was $16 \%$ in cesarean delivery group and this difference was also statistically significant $(\mathrm{p}=.03)$.

With regard to the postpartum depression based on Edinburgh's questionnaire and choosing a cutoff point 12, 8 (2.5\%) subjects in the vaginal delivery group and 12 (7.7\%) subjects in the

(c) The International Journal of Indian Psychology, ISSN 2348-5396 (e)| ISSN: 2349-3429 (p) | 175 


\section{Negative Effects and Factors Associated with Postpartum Depression on both Vaginal and Cesarean}

Delivery Groups

cesarean delivery group had the postpartum depression and the difference obtained was not statistically significant ( $\mathrm{p}=.27)(\mathrm{CI}: .6-3.83 ; \mathrm{OR}=1.52,95 \%)$.

In this study, the relationships between some variables such as age, history of premenstrual syndrome and a history of abortion with postpartum depression were statistically significant (Table 1). Logistic regression was used to control these variables and to estimate the matched odds ratio of the variable types of delivery. Logistic regression test results are shown in Table 2.

Table 2: Matched odds ratio, types of delivery, age, a history of abortion and a history of premenstrual syndrome based on the logistic regression analysis to evaluate the relationship between cesarean delivery and postpartum depression

\begin{tabular}{|c|c|c|c|c|}
\hline \multirow{2}{*}{ Variable } & \multirow{2}{*}{$\begin{array}{c}\text { Matched } \\
\text { odds ratio }\end{array}$} & \multicolumn{2}{|c|}{$\begin{array}{c}\text { Confidence interval } \\
95 \%\end{array}$} & \multirow{2}{*}{$\mathbf{P}$} \\
\hline & & $\begin{array}{l}\text { Upper } \\
\text { bound }\end{array}$ & $\begin{array}{l}\text { Lower } \\
\text { bound }\end{array}$ & \\
\hline $\begin{array}{l}\text { Types of delivery: Caesarean or } \\
\text { vaginal }\end{array}$ & $\begin{array}{c}1 \\
2.53\end{array}$ & \multicolumn{2}{|c|}{-93-6.88 } & .07 \\
\hline $\begin{array}{r}\text { A history of premenstrual } \\
\text { syndrome }\end{array}$ & 4.36 & \multicolumn{2}{|c|}{$1.48-12.83$} & .008 \\
\hline Abortion & .3 & \multicolumn{2}{|c|}{.04-2.49 } & .27 \\
\hline $\begin{array}{l}\text { Age groups } \\
30-18 \text { years } \\
\text { under } 18 \text { years } \\
\text { above } 30 \text { years }\end{array}$ & $\begin{array}{c}1 \\
1.92 \\
1.59 \\
\end{array}$ & \multicolumn{2}{|c|}{$\begin{array}{c}- \\
.2-17.89 \\
.51-4.92\end{array}$} & $\begin{array}{l}.57 \\
.42\end{array}$ \\
\hline
\end{tabular}

The goodness of the fit for the model was confirmed with $\mathrm{p}=.8$. As it can be observed, the probability of postpartum depression in cesarean delivery group after controlling the variables abortion, a history of premenstrual syndrome, and age was 2.53 times greater than the group with vaginal delivery (CI: .93-6.88; 95\%). Postpartum depression in people with a history of premenstrual syndrome is significantly higher than those having no such background $(\mathrm{p}=.008$; matched $\mathrm{OR}=4.36$ ). Postpartum depression level increased among the two age groups (namely under 18 and above 30 years) compared to the age group 18-30 years; however, the difference was not statistically significant $(\mathrm{p}=.57$ and $\mathrm{p}=.42)$.

\section{RESULTS}

In the present study, no statistically significant difference was observed between the two groups in terms of parents' education level, mother's occupation, and family's income level, marital satisfaction, and infants' gender, satisfaction from support provided by husbands and other family members, and acceptance of pregnancy. However, significant differences were found between the two groups in terms of age, type of house ownership, time and place of delivery, and

(c) The International Journal of Indian Psychology, ISSN 2348-5396 (e)| ISSN: 2349-3429 (p) | 176 


\section{Negative Effects and Factors Associated with Postpartum Depression on both Vaginal and Cesarean Delivery Groups}

living with other family members (Table 3). The mean age of vaginal delivery group (34.4 \pm 23.24 years) was lower than that for the cesarean delivery group $(73.4 \pm 23.26$ years $)(\mathrm{p}<.001)$.

Table 3: Relative and absolute frequency distribution of women's social and individual characteristics in the vaginal and cesarean delivery groups

\begin{tabular}{|c|c|c|c|c|}
\hline & Group & $\begin{array}{l}\text { Vaginal } \\
\text { delivery }\end{array}$ & $\begin{array}{r}\text { Cesarean } \\
\text { delivery }\end{array}$ & $\bar{P}$ \\
\hline \multirow[t]{4}{*}{ Mother's education level } & Primary school & $\begin{array}{l}20 \\
(5.13)\end{array}$ & (12) 17 & \multirow[t]{4}{*}{$25 / 0$} \\
\hline & Secondary school & (24) 36 & $(4.24) 29$ & \\
\hline & High school & $\begin{array}{l}73 \\
(3.49)\end{array}$ & $(4.51) 73$ & \\
\hline & University & $\begin{array}{l}19 \\
(8.12)\end{array}$ & $(2.16) 23$ & \\
\hline \multirow[t]{2}{*}{ Mother's occupation } & housewife & $\begin{array}{l}129 \\
(2.87)\end{array}$ & (4.82) 117 & \multirow[t]{2}{*}{$6 / 0$} \\
\hline & employed & $\begin{array}{l}19 \\
(8 / 12)\end{array}$ & $(2.17) 25$ & \\
\hline \multirow[t]{2}{*}{ Acceptance of pregnancy } & planned & $\begin{array}{l}132 \\
(2.89)\end{array}$ & (2.85) 121 & \multirow[t]{2}{*}{$24 / 0$} \\
\hline & unplanned & $\begin{array}{l}16 \\
(8 / 11)\end{array}$ & $(8.14) 21$ & \\
\hline \multirow[t]{3}{*}{ Marital satisfaction } & strongly satisfied & (25) 37 & (34.7) 35 & \multirow[t]{3}{*}{$4 / 0$} \\
\hline & satisfied & $\begin{array}{l}101 \\
(2.68)\end{array}$ & (4.70) 100 & \\
\hline & Dissatisfied & (8.6) 10 & $(9.4) 7$ & \\
\hline \multirow[t]{3}{*}{ satisfaction from husband's support } & strongly satisfied & $\begin{array}{l}58 \\
(2.39)\end{array}$ & (5.34) 49 & \multirow[t]{3}{*}{$4 / 0$} \\
\hline & satisfied & $\begin{array}{l}85 \\
(4.57)\end{array}$ & $(5.58) 83$ & \\
\hline & Dissatisfied & (4.3) 5 & (7) 10 & \\
\hline \multirow[t]{2}{*}{ Place of delivery } & State hospital & $\begin{array}{l}139 \\
(9.93)\end{array}$ & (3.87) 125 & \multirow[t]{2}{*}{$05 / 0$} \\
\hline & Private hospital & (1.6) 9 & $(7.12) 18$ & \\
\hline \multirow[t]{2}{*}{ Time of delivery } & day & $\begin{array}{l}81 \\
(1.55)\end{array}$ & (5.77) 110 & $00 / 0$ \\
\hline & night & $\begin{array}{l}66 \\
(9.44)\end{array}$ & $(5.22) 32$ & \\
\hline
\end{tabular}

The results showed that during the second week after delivery, the postpartum depression prevalence was 3.10 percent (5.9\% in the vaginal delivery group and $30.11 \%$ in selected cesarean delivery group) and no statistically significant difference was observed between the two groups in terms of postpartum depression prevalence.

(c) The International Journal of Indian Psychology, ISSN 2348-5396 (e)| ISSN: 2349-3429 (p) | 177 


\section{Negative Effects and Factors Associated with Postpartum Depression on both Vaginal and Cesarean Delivery Groups}

In two weeks after delivery, the postpartum depression mean score based on the Edinburgh's questionnaire was $64.4 \pm 58.7$ and $4.06 \pm 19.8$ in the vaginal and cesarean delivery groups, respectively. There was a statistically significant difference between the two groups (Table 4).

Table 4: Comparison of the depression average scores in two and eight weeks after delivery in vaginal and cesarean delivery groups

\begin{tabular}{|c|c|c|c|c|c|}
\hline \multirow[t]{2}{*}{ Group } & \multicolumn{2}{|c|}{$\begin{array}{l}\text { Vaginal } \\
\text { delivery }\end{array}$} & \multicolumn{2}{|c|}{ Cesarean delivery } & \multirow[t]{2}{*}{$\mathbf{p}$} \\
\hline & Mean & $\begin{array}{l}\text { Standard } \\
\text { deviation }\end{array}$ & Mean & \begin{tabular}{|l} 
Standard \\
deviation
\end{tabular} & \\
\hline $\begin{array}{l}\text { Depression score in } \\
\text { two weeks after } \\
\text { delivery }\end{array}$ & 7.58 & 4.64 & 8.19 & 4.06 & .066 \\
\hline $\begin{array}{l}\text { Depression score in } \\
\text { eight weeks after } \\
\text { delivery }\end{array}$ & 6.14 & 4.67 & 6.60 & 4.75 & .37 \\
\hline
\end{tabular}

In this study, there were 73 subjects in the vaginal delivery group and 75 subjects in the caesarean delivery group. The average age scores of women in the vaginal and caesarean delivery groups were $3.42 \pm 22.22$ years and $52.82 \pm 23.19$ years, respectively. The average age scores of the husbands of women in the vaginal and caesarean delivery groups were $3.57 \pm 27.1$ years and $3.55 \pm 27.07$ years, respectively. The average marriage age scores of women in the vaginal and caesarean delivery groups were $3.52 \pm 20.50$ and $2.95 \pm 20.52$ years, respectively. The difference was not statistically significant.

Regarding the women in the vaginal delivery group, they had high school education in 56.2\% cases and $95.9 \%$ cases were housewives and their husbands in 52.1\% cases had their own jobs. In $71.2 \%$ cases, they were tenants and had the house area per capita between $16-30 \mathrm{~m}^{2}$ in $64.4 \%$ cases. Considering the women in the caesarean delivery group, they had high school education in $56 \%$ cases and $94.7 \%$ cases were housewives and their husbands in $54.7 \%$ cases had their own jobs. In $68 \%$ cases, they were tenants and had the house area per capita between $16-30 \mathrm{~m}^{2}$ in $54.7 \%$ cases.

(c) The International Journal of Indian Psychology, ISSN 2348-5396 (e)| ISSN: 2349-3429 (p) | 178 
Negative Effects and Factors Associated with Postpartum Depression on both Vaginal and Cesarean Delivery Groups

Table 5: The distribution of women in terms of postpartum depression by the types of delivery in pregnant women having referred to health care centers of Shahid Beheshti University of Medical Sciences in 1984

\begin{tabular}{|l|c|c|c|c|c|c|}
\hline \multirow{2}{*}{$\begin{array}{c}\text { Depression } \\
\text { Type of delivery }\end{array}$} & $\mathbf{n}$ & $\mathbf{\%}$ & $\mathbf{n}$ & $\mathbf{\%}$ & $\mathbf{n}$ & $\mathbf{\%}$ \\
\cline { 2 - 7 } \multicolumn{1}{c|}{ Score below 12 } & \multicolumn{2}{c|}{ Score above 12 } & \multicolumn{2}{c|}{ Total } \\
\hline vaginal & 63 & 86.3 & 10 & 13.7 & 73 & 100 \\
\hline caesarean & 55 & 73.3 & 20 & 36.7 & 75 & 100 \\
\hline
\end{tabular}

\section{CONCLUSION}

Results show that the relative risk of depression in women with cesarean deliver (OR=2) with 95\% confidence level ranges from 1.2-3.9. This means that the rate of postpartum depression for women with cesarean delivery is twice as much as that for women having normal vaginal delivery. The attributed risk of cesarean delivery compared to vaginal delivery is ( $\mathrm{AR}=13 \%)$. This means that if women have normal vaginal delivery, their depression rate will be $13 \%$ lower.

\section{Acknowledgments}

The author appreciates all those who participated in the study and helped to facilitate the research process.

\section{Conflict of Interests}

The author declared no conflict of interests.

\section{REFERENCES}

1. Sadock BJ, Kaplan HI, Sadock VA. Kaplan \& Sadock's synopsis of psychiatry: behavioral sciences /clinical psychiatry. 9th ed. Philadelphia:Lippincott Williams and Wilkins;2003:870.

2. Lee D, Yip A, Chiu H, Leung $\mathrm{T}$, Chung $\mathrm{T}$. A psychiatric epidemiological study of postpartum Chinese women. Am J Psychiatry 2001 Feb;158(2):220-6.

3. O'Hara MW, Zekoski EM, Philipps LH, Wright EJ. Controlled prospective study of postpartum mood disorders: comparison of childbearing and nonchildbearing women. $\mathrm{J}$ Abnorm Psychol 1990 Feb;99(1):3-15.

4. Wilson LM, Reid AJ, Midmer DK, Biringer A, Carroll JC, Stewart DE. Antenatal psychosocial risk factors associated with adverse postpartum family outcomes. CMAJ 1996 Mar;154(6):785-99.

5. Areias ME, Kumar R, Barros H, Figueiredo E. Correlates of postnatal depression in mothers and fathers. Br J Psychiatry 1996 Jul;169(1):36-41.

6. Cooper PJ, Tomlinson M, Swartz L, Woolgar M, Murray L, Molteno C. Post-partum depression and the mother-infant relationship in a South African peri-urban settlement. $\mathrm{Br} \mathrm{J}$ Psychiatry 1999;175:554-8. 


\section{Negative Effects and Factors Associated with Postpartum Depression on both Vaginal and Cesarean Delivery Groups}

7. Dolatian M, Pooneh M, Alavi Majd H, Yazdjerdi M. [Mode of delivery and post partum depression]. [Article in Persian]. J Reprod Infert 2007;7(3):260-68.

8. Sword W, Landy CK, Thabane L, Watt S, Krueger P, Farine D, et al. Is mode of delivery associated with postpartum depression at 6 weeks: a prospective cohort study. BJOG 2011 Jul;118(8):966-977.

9. Carter FA, Frampton CM, Mulder RT. Cesarean section and postpartum depression: a review of the evidence examining the link. Psychosom Med 2006 Mar-Apr;68(2):321-30.

10. Clement S. Psychological aspects of caesarean section. Best Pract Res

1. Clin Obstet Gynaecol 2001 Feb;15(1):109-26.

11. Pai M. Medical interventions: caesarean sections as a case study. Econ Polit Wkly 2000;35(31):2755-61.

12. Silver RM, Landon MB, Rouse DJ, Leveno KJ, Spong CY, Thom EA, et al. Maternal morbidity associated with multiple repeat cesarean deliveries. Obstet Gynecol 2006 Jun;107(6):1226-32.

13. High infant mortality rate seen with elective c-section, Reuters Health, September 2006. Available at: http://www.medicineonline.com (2006-09-14). Retrieved on 2011.

14. Uwakwe R, Okonkwo JE. Affective (depressive) morbidity in puerperal Nigerian women: validation of the Edinburgh Postnatal Depression Scale. Acta Psychiatr Scand 2003 Apr;107(4):251-9.

15. Khorrami Rad A, Lotfi M, Shoori A. [Prevalence of post partum depression and related risk factors in Qom]. [Article in Persian]. Pazhoohandeh 2011;15(2):62-6.

16. Ukpong DI, Owolabi AT. Postpartum emotional distress: a controlled study of Nigerian women after caesarean childbirth. J Obstet Gynaecol 2006 Feb;26(2):127-9.

17. Boyce PM, Todd AL. Increased risk of postnatal depression after emergency caesarean section. Med J Aust 1992 Aug 3;157(3):172-4.

18. Fisher J, Astbury J, Smith A. Adverse psychological impact of operative obstetric interventions: a prospective longitudinal study. Aust N Z J Psychiatry 1997 Oct;31(5):728-38.

19. Adewuya AO, Fatoye FO, Ola BA, Ijaodala OR, Ibigbami SM. Sociodemographic and obstetric risk factors for postpartum depressive sypmtoms in Nigerian women. J Psychiatry Pract 2005 Sep;11(5):353-8.

\footnotetext{
How to cite this article: H Razmyar, S Radvar (2016), Negative Effects and Factors Associated with Postpartum Depression on both Vaginal and Cesarean Delivery Groups, International Journal of Indian Psychology, Volume 4, Issue 1, No. 79, ISSN:2348-5396 (e), ISSN:2349-3429 (p), DIP:18.01.098/20160304, ISBN:978-1-365-56745-2
} 